\title{
Classification Proposal of Metrological Techniques IN OCCUPATIONAL SAFETY AND HEALTH
}

\author{
Francisco Brocal ${ }^{\mathrm{a}, \mathrm{b}}$, Miguel A. Sebastián ${ }^{\mathrm{a}}$, Cristina González ${ }^{\mathrm{a}}$ \\ ${ }^{a} U N E D$, Escuela Técnica Superior de Ingenieros Industriales, C/ Juan del Rosal 12, Madrid 28040, España \\ ${ }^{b}$ Universidad de Alicante, Escuela Politénica Superior,Carretera San Vicente s/n, Alicante, 03690, España
}

\begin{abstract}
Given the multidisciplinary characteristics of Occupational Safety and Health (OSH), the applicable metrological techniques in this field are as numerous as they are difficult to classify. Added to this is the more important problem of those techniques that are currently pending development or updating according to current prevention needs.

Such needs are especially a priority in those industrial environments where the use of new technologies, besides generating traditional occupational risks, can generate other risks described by the European Agency for Safety and Health at Work as "New and Emerging Risks" in OSH.

This paper proposes a classification of the metrological techniques based on preventive criteria of a professional character, to solve the problems mentioned previously. This classification allows the identification of those techniques that require new research with the aim of adapting them to current demands of industrial processes.
\end{abstract}

Keywords: measurement; metrology; new and emerging risks; occupational risk; risk assessment; uncertainy
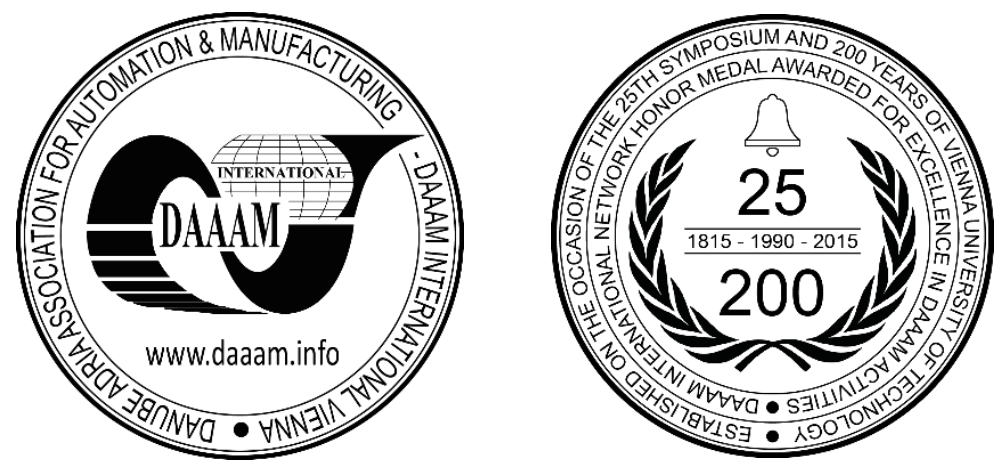

This Publication has to be referred as: Brocal, F[rancisco]; Sebastian, M[iguel] A[ngel] \& Gonzalez, C[risitina] (2016). Classification proposal of metrological techniques in occupational safety and health, Proceedings of the 26th DAAAM International Symposium, pp.0648-0655, B. Katalinic (Ed.), Published by DAAAM International, ISBN 978-3-90273407-5, ISSN 1726-9679, Vienna, Austria

DOI: $10.2507 / 26$ th.daaam.proceedings.088 


\section{Introduction}

Occupational health and safety (OHS) is a broad field of professional practice, which involves specialists from different disciplines including but not limited to engineers, occupational health physicians, physical and biological scientists, economists, and statisticians [1].

Among these professionals are OHS specialists. OHS specialists analyze many types of work environments and work procedures. Specialists inspect workplaces for adherence to regulations on safety, health, and the environment. They also design programs to prevent disease or injury to workers and damage to the environment [2].

There are mainly three ways to perform a risk assessment: qualitative way, semi quantitative way, and quantitative way [3]. Most OSH practitioners use semi-quantitative risk assessment methods to assess the risk of occupational accidents, in which the risk matrix is the principal metric used and the decisions regarding risk acceptance are supported by quantitative criteria [4]. Risk assessment has been traditionally involved in quantifying the risk of an incident based on two or more aspects, such as the likelihood of a risk (frequency) and the impact or consequence of the risk occurring (severity) [5]. In general, quantitative and semiquantitative risk matrices have limited ability to correctly reproduce the risk ratings implied by quantitative models especially if the two components of risk (e.g., frequency and severity) are negatively correlated [6].

According to Castejón [7], any risk assessment should begin with the process of identifying risk factors, to continue with the measurement of those factors that were unable to be eliminated in order to finish with a comparison of observed values with the reference values. When expressing the result of a measurement of a physical quantity, it must be some quantitative indication of the quality of the result, so that those who use this result can assess their suitability. Without such information, measurements cannot be compared with each other or with other reference values given in specifications or standards. It is therefore necessary to establish an easily understood and universally accepted procedure for characterizing the quality of a measurement result; that is, for evaluating and expressing its uncertainty [8].

Recent developments in risk assessment acknowledge the need to capture both quantitative and qualitative uncertainties in order to better understand and manage risks [9]. In safety literature this topic has been discussed already for a long time, and most likely will be an issue for the years to come [10]. If uncertainty cannot be properly treated in risk assessment, the risk assessment itself fails to perform as an informative tool for decision making, as intended [11].

Johansen y Rausand [12] consider that the ambiguity is a critical challenge that has not been fully recognized and explored in risk assessment; neither from a theoretical nor from a practical point of view. These authors define ambiguity as: the existence of multiple interpretations concerning the basis, content, and implications of risk information. Furthermore, they understand by risk information we mean descriptions of risk in a broad sense, such as scenarios, probability distributions, risk metrics, uncertainty factors, and sensitivities [13].

Risk metrics are essential for expressing, communicating, and using the results of risk analysis in risk informed decision-making. Not only do all metrics have limitations; the soundness of quantitative results is in itself a debated issue. A challenging topic for further research is the interpretation of uncertainty in relation to risk metrics [14].

Finally, it is also important to note the problem of terminologies used around the measurement uncertainty in the OHS field. In this regard, and as an example, in a study [15] on the use of leading indicators to measure OHS performance, the root of the term, indicator, is often substituted for metric, measure, or index.

\subsection{Research problem}

Given the multidisciplinary characteristics of OSH, the applicable metrological techniques in this field are as numerous as they are difficult to classify. Added to this is the more important problem of those techniques that are currently pending development or updating according to current prevention needs, among which are those related to measurement uncertainty. This parameter is essential for expressing, communicating, and using the results of occupational risk assessment.

\subsection{Goals}

The main goal of this work is to develop a proposal for the classification of the measurement techniques applied to measurement physical magnitude associated with the occupational risk assessment, especially related to the measurement and calculation of the accumulated dose reaching the affected worker. From this classification, it aims to establish a starting point to identify those techniques that require further research in order to adapt to the current demands of industrial processes, especially with regard to the measurement uncertainty.

\section{Measurement of risk factors}

As indicates Castejón [7], during the measurement of risk factors in the risk assessment process, it is important to clearly distinguish those situations where these factors are susceptible to cause accidents (immediate effects) to those 
which would produce possible injury, if it occurs, in the long term. In the first case, the measurement is specified in estimating the probability of the occurrence of the accident and the consequences of this for, from both data, assessing the risk. In the second, it is necessary to measure the intensity of the action of the risk factors (dose), which usually takes the form of the accumulated dose reaching the affected individual.

Regarding the safety design and acceptability of industrial technologies and activities, the risk assessment is a valuable technical tool which can be proactively used to inform with quantitative analyses the decision making process [11]. Zio y Aven [11] add that the techniques of uncertainty analysis sustaining the assessment are traditionally probabilistic, based on a Bayesian approach.

Regarding the risk assessment from the point of view of health, a quantitative assessment of exposure is necessary for more exact health risk evaluation. It consists of measuring the intensity or concentration, the variation in time, the total duration of exposure, as well as the number of workers exposed [16]. Biological and environmental monitoring starts with a study on the industrial hygiene work environment for identifying possible risks and contaminant sources and establishes the need for measurements [17]. As indicated by Castejón [7], for chemical and physical agents, the hypothesis that the decisive variable in relation to their ability to produce long-term damage is the accumulated dose, which can be defined as a magnitude proportional to the product of a factor intensity of exposure by the time exposure, is usually accepted. In the case of chemical and biological agents, the intensity factor usually refers to the environmental concentration. For physical agents, the factor is usually the energy intensity per unit time at which the worker is exposed.

From the above, the measurement techniques applied to risk assessment can be classified into two groups, depending on whether the measurement is applied to physical or non-physical magnitudes. In turn, these magnitudes may be environmental or non-environmental, and immediate or long-term harmful effects.

\section{Metrological techniques in OSH}

In this work, metrological techniques associated with risk assessment shall be understood as those applicable to the measurement of physical magnitudes, both environmental and non-environmental of labor origin and of immediate or long-term effects.

With regard to environmental metrological techniques, it shall be understood as those applied to the evaluation of risk factors of occupational exposure to chemical, biological and physical agents. Such techniques will be part, normally, of specific techniques in industrial hygiene. Regarding the non-environmental techniques, it shall be understood as those applicable to the assessment of risk factors other than chemical, biological and physical agents. These techniques will be part, normally, of specific technical safety and occupational ergonomics.

\subsection{Metrological techniques of non-environmental physical magnitudes}

Given the broad of the professional field in OHS [1], non-environmental physical magnitudes related to the risk assessment applied occupational safety, are also extent. In addition, techniques for uncertainty analysis that support these assessments are traditionally probabilistic, based on a Bayesian approach [11].

Similarly, the physical magnitudes related to ergonomics, are characterized as being associated with a broad array of fields of knowledge. According to the International Ergonomic Association [18], ergonomics promotes a holistic approach where physical, cognitive, social, organizational, environmental and other relevant factors should be considered. Thus, the field of action of this discipline is very broad, as follows: Physical ergonomics: is concerned with human anatomical, anthropometric, physiological and biomechanical characteristics as they relate to physical activity; Cognitive ergonomics: is concerned with mental processes, such as perception, memory, reasoning, and motor response, as they affect interactions among humans and other elements of a system; Organizational ergonomics: is concerned with the optimization of sociotechnical systems, including their organizational structures, policies, and processes.

Thus, as indicated by Haimes [19], the omnipresent adaptations of risk analysis by many disciplines, along with its deployment by industry and government agencies in decision making, have led to an unprecedented development of the theory, methodology, and practical tools.

For example, in a study carried out by Marhavilas et al. [20], the main methods and techniques of analysis and risk assessment were analyzed by reviewing the scientific literature published by six representative Elsevier journals covering the decade 2000-2009. In this regard, cited researchers identified 404 articles related to techniques relating to diverse areas like engineering, medicine, chemistry, biology, agronomics, etc. The risk analysis and assessment techniques analyzed are classified into the following three main categories, along with their frequencies: quantitative (65.63\%); qualitative (27.68\%); hybrid (6.70\%) (qualitative-quantitative, semi-quantitative).

Khan et al. [21] analyzed during 1990 and 2012 the evolution and development of methods and models applied to process safety and risk management. For this, the authors studied the publications of the main journals in the field. From the data obtained, it is observed that between 2007 and 2012, there are over 40 developments a year. In this study, the methods identified were classified into four types, as follows: qualitative, semi-quantitative, quantitative and hybrid (combination of quantitative and qualitative techniques). With this classification, these authors observed how related 
research, with quantitative and hybrid techniques, is increasing more than the qualitative or semi-quantitative related techniques.

\subsection{Metrological techniques of environmental physical magnitudes}

Environmental metrological techniques can be delimited with greater clarity than non-environmental techniques, as they are circumscribed to the assessment of risk factors of occupational exposure to chemical, biological and physical agents. Thus, the European directives related to such agents, from the perspective of the metrological aspects considered by them, are analyzed next.

\begin{tabular}{|c|c|c|c|c|c|c|}
\hline \multirow{2}{*}{\multicolumn{3}{|c|}{$\begin{array}{l}\text { METROLOGICAL TECHNIQUES } \\
\text { ENVIRONMENTAL PHYSICAL }\end{array}$}} & \multirow[t]{2}{*}{ DIRECTIVE } & \multicolumn{3}{|c|}{$\begin{array}{c}\text { METROLOGICAL } \\
\text { ASPECTS }\end{array}$} \\
\hline & & & & MA & MU & IM \\
\hline CHEMICAL & \multicolumn{2}{|c|}{ Chemical agents } & $\begin{array}{l}\text { Directive 98/24/CE [27] } \\
\text { Directive 2000/39/CE [28] }\end{array}$ & YES & NOT & NOT \\
\hline \multirow[t]{4}{*}{ BIOLOGICAL } & \multicolumn{2}{|c|}{ Biological agents } & Directive 90/679/CEE [29] & NOT & NOT & NOT \\
\hline & \multicolumn{2}{|l|}{ Noise } & Directive 2003/10/CE [30] & YES & YES & NOT \\
\hline & \multicolumn{2}{|l|}{ Vibrations } & Directive 2002/44/CE [31] & YES & YES & YES \\
\hline & \multicolumn{2}{|c|}{ Thermal Environment } & Directive 89/654/CEE [32] & NOT & NOT & NOT \\
\hline \multirow[t]{3}{*}{ PHYSICAL } & \multirow[t]{2}{*}{$\begin{array}{l}\text { Non-ionizing } \\
\text { radiation }\end{array}$} & $\begin{array}{l}\text { Artificial optical } \\
\text { radiation } \\
(100 \mathrm{~nm}-1 \mathrm{~mm}) \text { : } \\
\text { ultraviolet radiation, } \\
\text { visible radiation and } \\
\text { infrared radiation }\end{array}$ & Directive 2006/25/CE [33] & YES & YES & YES \\
\hline & & $\begin{array}{l}\text { Electromagnetic } \\
\text { fields } \\
(0 \mathrm{~Hz}-300 \mathrm{~Hz})\end{array}$ & Directive 2013/35/UE [34] & YES & YES & YES \\
\hline & \multicolumn{2}{|c|}{ Ionizing radiation } & $\begin{array}{l}\text { Directive 90/641/Euratom [25] } \\
\text { Directive 80/836/Euratom [26] }\end{array}$ & YES & NOT & NOT \\
\hline
\end{tabular}

Table 1. Classification of the metrological techniques of environmental physical magnitudes

In Table 1, the main results are shown, for which the following criteria has been applied:

a) Selection of directives: directives have been selected specific to the OSH field;

b) Classification of agents and associated directives: chemical and biological agents, have specific directives for each of them. Physical agents have been ordered taken as reference the classification developed by [22], so that the noise, vibration, artificial optical radiation and electromagnetic fields are agents associated with specific directives. Heat and cold are integrated in a directive of general application in the workplace. Heat and cold are integrated in a directive of general application in the workplace. Regarding the European framework which regulate ionizing radiation, is particularly broad and complex, where as with other contaminants (for example chemicals), exist directives which are applicable both in the OSH field as to the general population (as occurs with radioactive installations through Directive 96/29/Euratom [23], or to medical exposures through Directive 97/43/Euratom [24]). In this case, only Directive 90/641/Euratom [25] is contemplated, and as an exception to the first criteria, the Directive 80/836/ Euratom [26] is considered too -according first article of Directive 90/641/Euratom [25]-);

c) Metrological aspects: each selected directive has been analyzed with the purpose of determining if the assessment methodology considered contemplates (YES) or does not contemplate (NOT) the following: (1) measurement agent (MA); (2) measurement uncertainty (MU); (3) as an alternative to the measurement, the possibility of using the information provided by the manufacturers of the work equipment that can generate specific agents (IM).

Regarding the results shown in Table 1, the main metrological aspects considered (YES) for each directive are shown in greater detail:

(1) Measurement uncertainty (MU): Noise: Directive 2003/10/CE [30]: the measurement uncertainty is not covered directly. Instead, it is indicated that the assessment of the measurement results shall take into account the measurement inaccuracies determined in accordance with metrological practice; Vibrations: Directive 2002/44/CE [31]: It is not covered directly the measurement uncertainty. In its place the Directive considered the following standards: handarm vibration (HAV): ISO 5349-1: 2001 [35]; ISO 5349-2: 2001 [36]; whole body vibration (WBV): ISO 2631-1: 1997 [37]. Of these three standards ISO 5349-2 [36] only considers the uncertainty; It matches that this standard is the only of 
the three specific application to the workplace; Artificial optical radiation: Directive 2006/25/CE [33]: the methodology applied in assessment, measurement and/or calculations shall follow the standards of the International Electrotechnical Commission (IEC) in respect of laser radiation and the recommendations of the International Commission on Illumination (CIE) and the European Committee for Standardisation (CEN) in respect of non-coherent radiation. In exposure situations which are not covered by these standards and recommendations, and until appropriate EU standards or recommendations become available, assessment, measurement and/or calculations shall be carried out using available national or international science-based guidelines; Electromagnetic fields: Directive 2013/35/UE [34]: in order to facilitate the implementation of this Directive the Commission shall make available non-binding practical guides at the latest six months before 1 July 2016. Those practical guides shall relate, among others, to guidance for dealing with measurements and calculations uncertainties. If compliance with the exposure limit values cannot be reliably determined on the basis of readily accessible information, the assessment of the exposure shall be carried out on the basis of measurements or calculations. In such a case, the assessment shall take into account uncertainties concerning the measurements or calculations, such as numerical errors, source modelling, phantom geometry and the electrical properties of tissues and materials, determined in accordance with relevant good practice.

(2) Possibility of using the information provided by the manufacturers (IM): Vibrations: Directive 2002/44/CE [31]: the level of exposure to mechanical vibration may be assessed by means of observation of specific working practices and reference to relevant information on the probable magnitude of the vibration corresponding to the equipment or the types of equipment used in the particular conditions of use, including such information provided by the manufacturer of the equipment. That operation shall be distinguished from measurement, which requires the use of specific apparatus and appropriate methodology; Artificial optical radiation: Directive 2006/25/CE [33]: it is not necessary for employers to repeat the measurements or calculations already undertaken by the manufacturer to determine compliance with the essential safety requirements of such equipment as specified in the applicable Community Directives, provided that the equipment has been properly and regularly maintained. In both exposure situations contemplated in (2), the assessment may take account of data provided by the manufacturers of the equipment when it is covered by relevant Community Directives; Electromagnetic fields: Directive 2013/35/UE [34]: for the purpose of the assessment, the employer shall also be entitled, where relevant, to take into account the emission levels and other appropriate safetyrelated data provided, by the manufacturer or distributor, for the equipment, in accordance with relevant Union law, including an assessment of risks, if applicable to the exposure conditions at the workplace or place of installation.

The set of results obtained in this section, it can be shown schematically in Fig. 1.

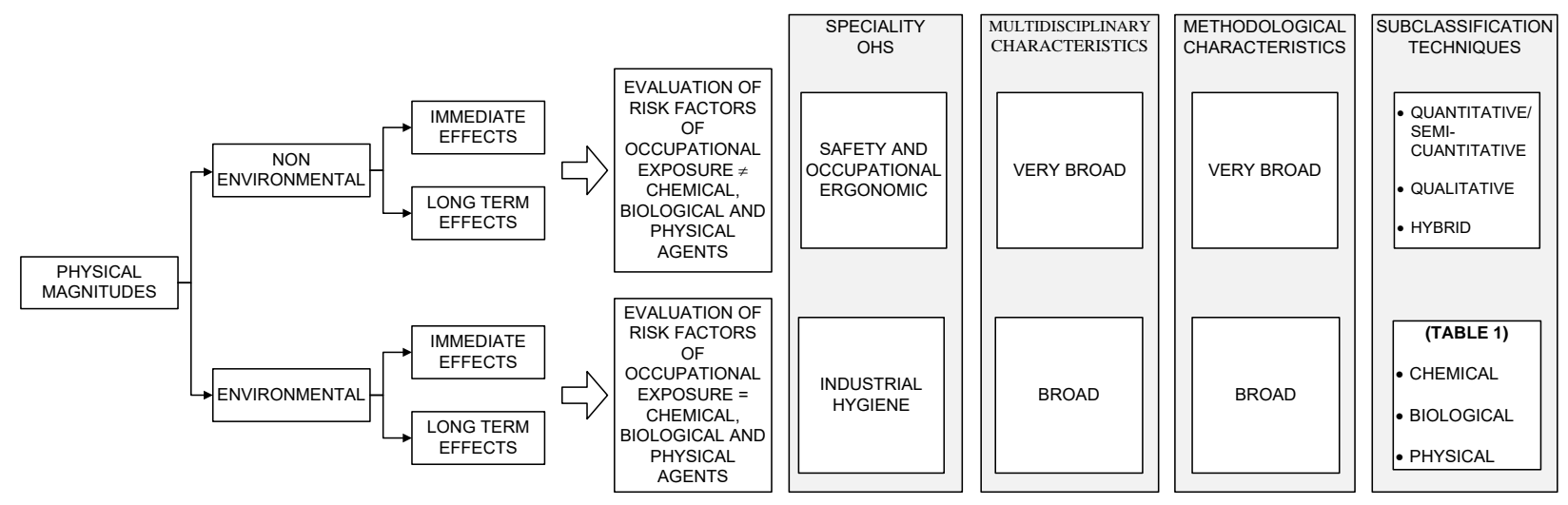

Fig. 1. Classification proposal of metrological techniques in $\mathrm{OSH}$

\section{Analysis and discussion of results}

The process of measuring risk factors and associated uncertainty analysis is part of the risk assessment process. However, depending on the characteristics of the risk assessment methodology, the process of measurement and uncertainty analysis can be performed on physical magnitudes or non-physical magnitudes. In the case of analysis of physical magnitudes, the measurement process will be associated with the use of instrumentation, and therefore metrological techniques should be applied. In other cases, other measurement techniques are used.

With the proposed classification of metrological techniques, it is possible to differentiate between environmental and non-environmental variables. The main advantage of this classification is that it allows an approach to differentiate between OSH specific methodologies and other methodologies of a more general scope, as shown in Fig. 1.

For this, the environmental agents considered have been mainly analyzed from the perspective of industrial hygiene. This approach focuses on the dose received by the exposed worker. Thus, the methodologies associated with environmental variables are likely to be linked to concrete European directives, as shown in Table 1, and thereby allow a starting point relative to metrological analysis of each of these variables. However, regarding the non-environmental variables, it has been verified by analysis of different research, especially those of [20] and [21], that there is a significant 
and continuing growth in the number of risk assessment methodologies. In addition, these methodologies are characterized as being related to many different professional fields. Such circumstances form a broad and complex metrological area.

Environmental agents should also be analyzed from the point of view of ergonomics and safety perspectives. From the perspective of these disciplines, the complexity of the methodological framework used in risk assessment matches the scenario identified through studies by [20] and [21].

With regard to the 10 directives analyzed, in relation to environmental agents, 9 of which contemplate the measurement process, and only 4 also provide for the consideration of uncertainty, more or less directly. In the best case, that is when directives consider the measuring agent (MA) and the measurement uncertainty (MU), two aspects are mainly observed: (a) with respect to the specific methodologies used, in the best case, the information is incomplete. Such a circumstance occurs with noise, where the Directive contains the standard ISO 1999: 1990 [38] (now ISO 1999/2013 [39]). However, since the publication of the Directive in 2003, it was not until the publication of standard ISO 9612 in 2009 [40], to provide a methodology to determine the exposure to noise at work, using different measurement strategies and uncertainty analysis in accordance with metrological practice; (b) three directives, include the possibility to use the measurement results of the manufacturer in the risk assessment process, avoiding, where appropriate, measurement in the workplace (in any case, in any risk assessment process the information provided by the manufacturer should be considered). In these three cases, a representative example from the point of view of the definition of the procedure to be used "by estimation", is the relative to hand-arm vibration through the standard CEN/TR 15350: 2013 [41]. However, in the application of that standard there are aspects concerning the treatment of the uncertainty of the data (acceleration) that remain unresolved. In addition, there is currently no equivalent standard in relation to whole-body vibration.

The previous considerations are based on a traditional approach to the risk. Using a broader perspective, where risks characterized as new and emerging can also be considered, there are even more challenging unresolved metrological issues. An example of the above, in the use of chemical agents, is occupational exposure to nanoparticles [42]. In this regard, there are many metrological issues that have yet to be better defined at nanoscale [43]. The technical and scientific strategies focused on new and emerging issues of concern can be improved by adopting the NER model proposed by [44].

\section{Conclusion}

The measurement techniques applied to the evaluation methodologies of occupational risk evaluation are characterized as being associated with many fields of knowledge, and therefore a multitude of measurement procedures on both physical and non-physical magnitudes.

In both cases, there is growing scientific and technological interest in the treatment and uncertainty analysis.

Regarding physical magnitudes, with this paper a classification of metrological techniques has been developed, which allow an approach to differentiate OSH specific methodologies from other methodologies of a more general scope. In the first case, it has been revealed, with the directives analyzed, that there is a basic problem in relation to the definition of measurement strategies and uncertainty analysis. In the second case, the problem may be even greater because of the number and diversity of new methodologies that are published every year.

To dimension and define in detail the problems identified, and consequently propose solutions, it is necessary to develop new researches focused on specific risk assessment methodologies. These needs are more relevant in the field of new and emerging occupational risks.

\section{References}

[1] J.S. Annan, E. K. Addai, S.K. Tulashie, A Call for Action to Improve Occupational Health and Safety in Ghana and a Critical Look at the Existing Legal Requirement and Legislation, Safety and Health at Work, 6 (2015) 146-150.

[2] BLS (Bureau of Labor Statistics), U.S. Department of Labor, Occupational Outlook Handbook, 2014-15 Edition, Occupational Health and Safety Specialists, on the Internet at http://www.bls.gov/ooh/healthcare/occupationalhealth-and-safety-specialists.htm (visited August 12, 2015).

[3] A. S. Markowski, M. Sam Mannan, Fuzzy risk matrix, Journal of Hazardous Materials.159 (2008) 152-157.

[4] M.A. Rodrigues, P.M. Arezes, C.P. Leão, Risk decision: main constraints and approaches. In: ASME 2012 International Mechanical Engineering Congress and Exposition, Design, Materials and Manufacturing, Parts A, B, and C, November 9-15, Houston, Texas, USA, vol. 3 (2012), pp. 1757-1763.

[5] N. Azadeh-Fard, A. Schuh, E. Rashedi, J.A. Camelio, Risk assessment of occupational injuries using Accident Severity Grade, Safety Science, Volume 76 (2015) 160-167.

[6] A.T. Cox, L, What's wrong with risk matrices? Risk Anal. 28 (2008) 497-512.

[7] E. Castejón, Evaluación de Riesgos, in C. Ruiz Frutos, J. Delclós, E. Ronda, A.M. García, F.G. Benavides (Eds.), Salud laboral. Conceptos y técnicas para la prevención de riesgos laborales, fourth ed., Barcelona: Elsevier Masson, Barcelona, 2014, pp. 213-224.

[8] JCGM (Grupo de Trabajo 1 del Comité Conjunto de Guías en Metrología), Evaluación de datos de medición Guía para la Expresión de la Incertidumbre de Medida, Centro Español de Metrología, 2008.

[9] G. Grote, Promoting safety by increasing uncertainty - Implications for risk management, Safety Science, 71 (2015) 71-79. 
[10] P. Swuste, E. Albrechtsen, J. Hovden, Towards safety through advanced solutions, Safety Science, 71 (2015) 6970.

[11] E. Zio, T. Aven, Industrial disasters: Extreme events, extremely rare. Some reflections on the treatment of uncertainties in the assessment of the associated risks, Process Safety and Environmental Protection, 91 (2013) 31 45.

[12] I.L. Johansen, M. Rausand, Ambiguity in risk assessment, Safety Science, 80 (2015) 243-251.

[13] T. Aven, Foundations of Risk Analysis, second ed., Wiley, Hoboken, NJ, 2012.

[14] I.L. Johansen, M. Rausand, Foundations and choice of risk metrics, Safety Science, 62 (2014) 386-399.

[15] S. Sinelnikov, J. Inouye, S. Kerper, Using leading indicators to measure occupational health and safety performance, Safety Science (2015) 240-248.

[16] J. Rantanen, I.A. Fedotov, Standards, Principles and approaches in occupational health services, International Labour Organization, 2002.

[17] R. F. Herrick, Higiene Industrial, in: J. Finklea, H. Coppée, V. Hunt, R. Kraus, W. Laurig, J. Messite, S. Sauter, J. Spiegel, C. Soskolne, B. Terracini, M. Myers, (Eds), Enciclopedia de Salud y Seguridad en el Trabajo (Organización Internacional del Trabajo), Ministerio de Trabajo y Asuntos Sociales Subdirección General de Publicación ,1998), pp. 30.01-30.08.

[18] IEA (International Ergonomic Association), on the Internet at http://www.iea.cc/whats/ (visited September 1, 2015).

[19] Y.Y. Haimes, Risk modelling, assessment, and management (3rd ed.). A John Wiley \& Sons Inc. Publication, 2009.

[20] P.K. Marhavilas, D. Koulouriotis, V. Gemeni, Risk analysis and assessment methodologies in the work sites: On a review, classification and comparative study of the scientific literature of the period 2000-2009, Journal of Loss Prevention in the Process Industries, 24, (2011), 477-523.

[21] F. Khan, S. Rathnayaka, S. Ahmed, Methods and models in process safety and risk management: Past, present and future, Process Safety and Environmental Protection, 98 (2015) 116-147.

[22] F. Brocal, Metodología para la Identificación de Riesgos Laborales Nuevos y Emergentes en los Procesos Avanzados de Fabricación Industrial (Methodology for Identifying New and Emerging Occupational Risks in Advanced Industrial Manufacturing Processes). (Doctoral Thesis). Madrid: UNED, 2014.

[23] Directive 96/29/Euratom of 13 May 1996 laying down basic safety standards for the protection of the health of workers and the general public against the dangers arising from ionising radiation (OJ L 159, 29.6.1996, p. 1-114).

[24] Directive 97/43/EURATOM of 30 June 1997 on health protection of individuals against the dangers of ionizing radiation in relation to medical exposure, and repealing Directive 84/466/Euratom (OJ L 180, 9.7.1997, p. 22-27).

[25] Directive 90/641/Euratom of 4 December 1990 on the operational protection of outside workers exposed to the risk of ionizing radiation during their activities in controlled areas (OJ L 349, 13.12.1990, p. 21-25).

[26] Directive 80/836/Euratom of 15 July 1980 amending the Directives laying down the basic safety standards for the health protection of the general public and workers against the dangers of ionizing radiation (OJ L 246, 17.9.1980, p. 1-72).

[27] Directive 98/24/EC of 7 April 1998 on the protection of the health and safety of workers from the risks related to chemical agents at work (fourteenth individual Directive within the meaning of Article 16(1) of Directive 89/391/EEC) (OJ L 131, 5.5.1998, p. 11-23).

[28] Commission Directive 2000/39/EC of 8 June 2000 establishing a first list of indicative occupational exposure limit values in implementation of Council Directive 98/24/EC on the protection of the health and safety of workers from the risks related to chemical agents at work (Text with EEA relevance) (OJ L 142, 16.6.2000, p. 47-50).

[29] Directive 90/679/EEC of 26 November 1990 on the protection of workers from risks related to exposure to biological agents at work (seventh individual Directive within the meaning of Article 16 (1) of Directive 89/391/EEC) (OJ L 374, 31.12.1990, p. 1-12).

[30] Directive 2003/10/EC of the European Parliament and of the Council of 6 February 2003 on the minimum health and safety requirements regarding the exposure of workers to the risks arising from physical agents (noise) (Seventeenth individual Directive within the meaning of Article 16(1) of Directive 89/391/EEC) (OJ L 42, 15.2.2003, p. 38-44).

[31] Directive 2002/44/EC of the European Parliament and of the Council of 25 June 2002 on the minimum health and safety requirements regarding the exposure of workers to the risks arising from physical agents (vibration) (sixteenth individual Directive within the meaning of Article 16(1) of Directive 89/391/EEC) - Joint Statement by the European Parliament and the Council (OJ L 177, 6.7.2002, p. 13-20).

[32] Directive 89/654/EEC of 30 November 1989 concerning the minimum safety and health requirements for the workplace (first individual directive within the meaning of Article 16 (1) of Directive 89/391/EEC) (OJ L 393, 30.12.1989, p. 1-12).

[33] Directive 2006/25/EC of the European Parliament and of the Council of 5 April 2006 on the minimum health and safety requirements regarding the exposure of workers to risks arising from physical agents (artificial optical radiation) (19th individual Directive within the meaning of Article 16(1) of Directive 89/391/EEC) (OJ L 114, 27.4.2006, p. 38).

[34] Directive 2013/35/EU of the European Parliament and of the Council of 26 June 2013 on the minimum health and safety requirements regarding the exposure of workers to the risks arising from physical agents (electromagnetic fields) (20th individual Directive within the meaning of Article 16(1) of Directive 89/391/EEC) and repealing Directive 2004/40/EC (OJ L 179, 29.6.2013, p. 1-21). 
[35] ISO. Mechanical vibration. Measurement and evaluation of human exposure to hand-transmitted vibration. Part 1: General requirements. ISO 5349-1:2001. Geneva: ISO, 2001.

[36] ISO. Mechanical vibration. Measurement and evaluation of human exposure to hand-transmitted vibration. Part 2: Practical guidance for measurement at the workplace. ISO 5349-2:2001. Geneva: ISO, 2001.

[37] ISO. Mechanical vibration and shock. Evaluation of human exposure to whole-body vibration. Part 1: General requirements. ISO 2631-1:1997. Geneva: ISO, 1997.

[38] ISO. Acoustics -- Determination of occupational noise exposure and estimation of noise-induced hearing impairment. ISO 1999:1990. Geneva: ISO, 1990.

[39] ISO. Acoustics. Estimation of noise-induced hearing loss. ISO 1999:2013. Geneva: ISO, 2013.

[40] ISO. Acoustics. Determination of occupational noise exposure. Engineering method. ISO 9612:2009. Geneva: ISO, 2009.

[41] CEN. Mechanical vibration - Guideline for the assessment of exposure to hand-transmitted vibration using available information including that provided by manufacturers of machinery. CEN/TR 15350:2013. Geneva: CEN, 2013.

[42] Kazula et al., Workplace exposure to nanoparticle, Luxembourg: Office for Official Publications of the European Communities, 2009.

[43] M. Rossi et al., Scientific basis of nanotechnology, implications for the food sector and future trends, Trends in Food Science \& Technology, 40 (2014) 127-148.

[44] F. Brocal, M.A. Sebastián, Analysis and Modeling of New and Emerging Occupational Risks in the Context of Advanced Manufacturing Processes, Procedia Engineering, 100 (2015) 1150-1159. 